\title{
Endoscopic Submucosal Dissection Followed by Concurrent Chemoradiotherapy in Patients with Early Esophageal Cancer with a High Risk of Lymph Node Metastasis
}

\author{
Hee Kyung Kim, Weon Jin Ko, Chang-II Kwon, Ga Won Song, In Kyun Yoo, Ji Hyun Song, Hak Su Kim and Joo Young Cho \\ Digestive Disease Center, CHA Bundang Medical Center, CHA University, Seongnam, Korea
}

Endoscopic submucosal dissection is recommended as an alternative therapy for early esophageal cancer. However, achieving curative resection in this procedure remains controversial since precise prediction of lymph node metastasis can be difficult. Here, we present the preliminary results of endoscopic submucosal dissection followed by concurrent chemoradiotherapy for early esophageal cancer with a high risk of lymph node metastasis. From May 2006 to January 2014, six patients underwent concurrent chemoradiotherapy after endoscopic submucosal dissection with a median follow-up period of 63 months. No complications were encountered during concurrent chemoradiotherapy. Although local recurrence did not occur in all patients, two patients were diagnosed with metachronous cancer. Overall, the survival rate was $100 \%$. Thus, endoscopic submucosal dissection followed by concurrent chemoradiotherapy may be a feasible treatment for early esophageal cancer in patients with a high risk of lymph node metastasis. Future prospective large-scale studies are warranted to confirm our results. Clin Endosc 2019;52:502-505

Key Words: Early esophageal cancer; Concurrent chemoradiotherapy; Endoscopic submucosal dissection

\section{INTRODUCTION}

Esophageal cancer is one of the most common and life-threating malignancies, and its incidence is rapidly increasing. ${ }^{1}$ Poor esophageal cancer prognosis can be attributed to the easy spreading of cancer cells owing to the thin adventitial layer of the esophagus and to the well-developed lymph node chains around the esophagus. Therefore, the surgical curative rate of esophageal cancer is low. Additionally, approximately $40 \%$ of esophageal cancer patients experience surgical complications after undergoing esophagectomy and their quality of life may be severely compromised after surgery.

Received: October 10, 2018 Revised: January 14, 2019

Accepted: January 19, 2019

Correspondence: Joo Young Cho

Digestive Disease Center, CHA Bundang Medical Center, CHA University, 59

Yatap-ro, Bundang-gu, Seongnam 13496, Korea

Tel: +82-31-780-5641, Fax: +82-31-780-5005, E-mail: cjy6695@cha.ac.kr

ORCID: https://orcid.org/0000-0001-9085-0313

(cc) This is an Open Access article distributed under the terms of the Creative Commons Attribution Non-Commercial License (http://creativecommons.org/ licenses/by-nc/3.0) which permits unrestricted non-commercial use, distribution, and reproduction in any medium, provided the original work is properly cited.
Therefore, attempts have been made to develop a multi-disciplinary approach for esophageal cancer treatments. ${ }^{2}$ Endoscopic resection can be used to treat early esophageal cancer (EEC) limited to the mucosa that is not complicated by lymph node metastasis (LNM). However, there are currently no well-established therapies for patients at risk for LNM, which is confirmed by the final pathologic diagnosis after endoscopic resection. ${ }^{3}$ Although an esophagectomy can be an additional treatment option for these patients, it is accompanied by a high postoperative complication rate in elderly patients. Thus, ongoing researches have focused on concurrent chemoradiotherapy (CCRT) as a potential alternative therapy for those patients. In recently reported studies, CCRT outcomes were comparable with surgical outcomes. ${ }^{4,5}$ Here, we report our experiences in performing esophageal endoscopic submucosal dissections (ESDs) followed by adjuvant CCRT in EEC patients with a high risk of LNM. 


\section{CASE REPORT}

We conducted a retrospective review of the database in the Digestive Disease Center of Bundang CHA Hospital (Seongnam, Korea) and identified 28 patients who were diagnosed with EEC and consequently underwent ESD between May 2006 and January 2014. The ESD was performed according to the standard procedure of the Hospital (Fig. 1). The specimens were fixed with formalin, cut into 2-mm thick sections, and stained with hematoxylin and eosin. All sliced tissue sections were immunohistochemically stained. The specimens of four patients were positive for lympho-vascular invasion, while the final pathological findings of the ESD specimens of two other patients revealed submucosal invasion. Based on the final pathological report, we recommended esophagectomy for these patients. However, all of them refused to undergo surgery despite having a high risk of LNM. Hence, instead of surgery, these patients received CCRT, which included highdose radiotherapy (60 Gy) combined with $1,000 \mathrm{mg} / \mathrm{m}^{2}$ cisplatin and 1,000 mg/m $\mathrm{m}^{2}$-fluorouracil (5-FU). Informed consent was obtained from all six patients before performing CCRT. The patients visited the clinic every six months. Laboratory tests, esophagogastroduodenoscopy, and chest computed tomography were performed at each visit. The clinical outcomes of endoscopic resection and the subsequent long-term outcomes, including adverse events, local recurrences, and metachronous recurrences, along with the overall survival and disease-free survival rates, were investigated.

The characteristics and comorbidities of all six patients (5 males, 1 female) are presented in Tables 1 and 2. The mean age of our patients was 61.5 years. The final pathological type of EEC was squamous cell carcinoma in all patients. The mean size of the pathological specimen was $30.3 \times 18.5 \mathrm{~mm}$, and the mean tumor-free lateral margin length was $3.2 \mathrm{~mm}$. During the procedure, perforation occurred in only one patient and was simply treated using a hemoclip. The other patients did not exhibit any major complications. Regarding the pathological lesion depth, EEC was limited to the lamina propria (M2) in two patients and to the muscularis mucosa (M3) in two other patients. Even though four of our patients had cancer
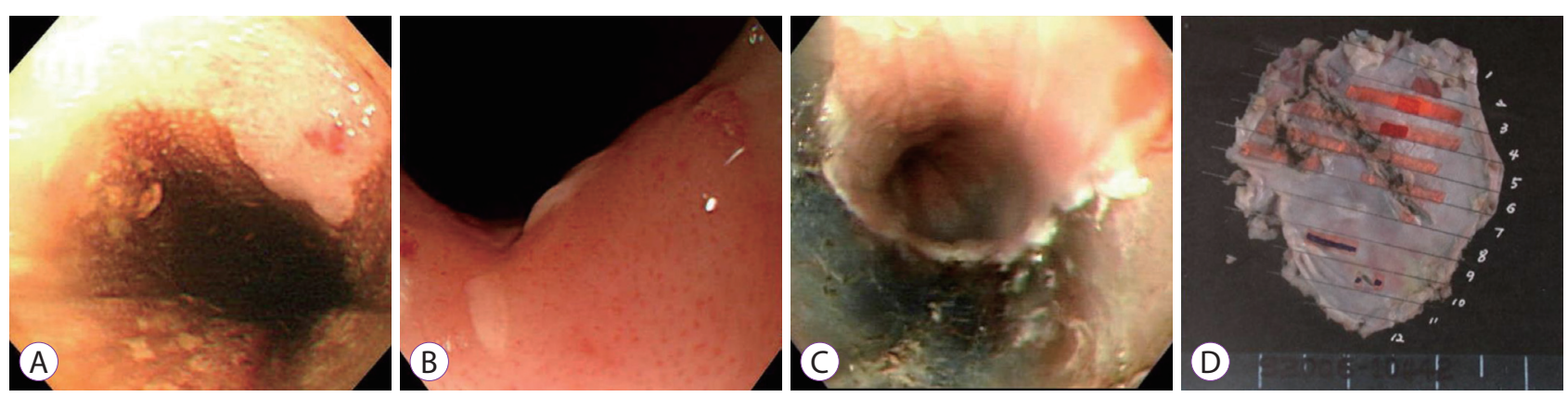

Fig. 1. (A) A flat elevated mucosal lesion, $2.5-3.0 \mathrm{~cm}$ in size and located $20-23 \mathrm{~cm}$ from the upper incisor, was detected during an esophagogastroduodenoscopy; (B) Magnification endoscopy revealed dilatation and irregular caliber changes of the intrapapillary capillary loop (IPCL-V1); (C) ESD was performed based on the biopsy results that suggested the presence of squamous cell carcinoma; (D) The specimen was $22 \times 13 \mathrm{~mm}$ in size.

Table 1. Six Cases of Concurrent Chemoradiotherapy after ESD for the Treatment of Superficial Esophageal Cancer

\begin{tabular}{|c|c|c|c|c|c|c|c|c|c|c|c|c|}
\hline \multirow[b]{2}{*}{ No. } & \multirow{2}{*}{$\begin{array}{c}\text { Date of } \\
\text { diagnosis }\end{array}$} & \multirow{2}{*}{$\begin{array}{l}\text { Age } \\
\text { /Sex }\end{array}$} & \multirow{2}{*}{$\begin{array}{c}\text { Location } \\
\text { of tumor } \\
\text { (from U.I) }\end{array}$} & \multirow{2}{*}{$\begin{array}{c}\text { Pre-ESD } \\
\text { diagnosis }\end{array}$} & \multicolumn{6}{|c|}{ ESD results } & \multicolumn{2}{|c|}{ Progress } \\
\hline & & & & & Diagnosis & $\begin{array}{l}\text { Size } \\
(\mathrm{mm})\end{array}$ & $\begin{array}{l}\text { Depth of } \\
\text { invasion }\end{array}$ & $\begin{array}{c}\text { Resection } \\
\text { margin }\end{array}$ & $\begin{array}{l}\text { Lymphatic } \\
\text { invasion }\end{array}$ & $\begin{array}{l}\text { Vascular } \\
\text { invasion }\end{array}$ & $\begin{array}{c}\text { Follow-up } \\
\text { period (mo) }\end{array}$ & $\begin{array}{c}\text { Recur- } \\
\text { rence }\end{array}$ \\
\hline 1 & 2006-09 & $58 / \mathrm{M}$ & $20 \mathrm{~cm}$ & SqCC, MD & SqCC, MD & $22 \times 13$ & M3 & Free & Positive & Negative & 124 & No \\
\hline 2 & 2010-07 & $61 / \mathrm{M}$ & $25 \mathrm{~cm}$ & SqCC, WD & SqCC, WD & $27 \times 23$ & $\begin{array}{c}\text { SM3; } \\
450 \mu \mathrm{m}\end{array}$ & Free & Negative & Negative & 66 & No \\
\hline 3 & $2010-10$ & $69 / \mathrm{F}$ & $32 \mathrm{~cm}$ & SqCC, WD & SqCC, WD & $25 \times 18$ & M2 & Free & Positive & Negative & 75 & No \\
\hline 4 & 2012-01 & $55 / \mathrm{M}$ & $32 \mathrm{~cm}$ & SqCC, WD & SqCC, WD & $22 \times 41$ & M2 & Free & Positive & Negative & 60 & No \\
\hline 5 & 2014-01 & $65 / \mathrm{M}$ & $28 \mathrm{~cm}$ & SqCC, MD & SqCC, MD & $42 \times 22$ & $\begin{array}{c}\text { SM1; } \\
150 \mu \mathrm{m}\end{array}$ & Free & Positive & Negative & 30 & No \\
\hline 6 & 2014-07 & $67 / \mathrm{M}$ & $32 \mathrm{~cm}$ & SqCC, MD & SqCC, MD & $25 \times 13$ & M3 & Free & Positive & Negative & 29 & No \\
\hline
\end{tabular}

ESD, endoscopic submucosal dissection; M, mucosa; MD, moderately-differentiated; SM, submucosa; SqCC, squamous cell carcinoma; U.I, upper incisor; WD, well-differentiated. 
limited to the mucosal layer, they were positive for lymphovascular invasion. In the remaining two patients, EEC invaded the upper region of the submucosa at depths of $150 \mu \mathrm{m}$, in the remaining two patients, EEC invaded the upper region of the submucosa at depths of $150 \mu \mathrm{m}$ (SM1) and $450 \mu \mathrm{m}$ (SM3). We were able to achieve a clear resection margin, even in the two patients who had submucosal invasion (Fig. 2). All patients were treated with adjuvant CCRT with no complications reported during treatment.

The median follow-up period was 63 (range, 29-124) months. During that period, local recurrence was not reported in any of our patients; however, metachronous cancer was detected in two patients after 3 and 7 years, respectively. One patient underwent esophagectomy with gastric reconstruction; the other patient received ESD followed by photodynamic therapy to prevent recurrence as pathological findings of his ESD specimen indicated positive lateral margins. Unfortunately, during the follow-up period, two of our patients showed esophageal stricture as a complication arising after CCRT; we performed balloon dilation to treat this complication.

\section{DISCUSSION}

The outcomes of endoscopic resection of EEC are comparable to those of surgical treatment, with low complication rates and a good quality of life. ${ }^{6}$ In a recently conducted single-center study, ESD was reported to be an effective treatment for superficial esophageal neoplasm (EEC and dysplasia). ${ }^{7}$ However, a standard therapy has not yet been established for patients with a high risk of LNM, which is usually confirmed through the final pathological findings of the ESD specimens. Previous studies comparing surgical resection with CCRT reported that the 2-year survival rate for the surgical group was $40 \%-65 \%$, and $35 \%-85 \%$ for the CCRT group without any statistically significant differences. ${ }^{5,6}$ An esophagectomy was reportedly associated with a hospital stay of 10-12 days, a postoperative complication rate of $40 \%$, and a $5 \%$ mortality rate. ${ }^{8}$ These results suggest that CCRT could be more beneficial than surgery in elderly patients who have a higher risk of complications after an esophagectomy. In our case series comprising six patients, there were no local recurrences after

Table 2. Patient Comorbidities

\begin{tabular}{lccl}
\hline Patient no. & Date of diagnosis & Age/Diagnosis & \\
\hline 1 & $2006-09$ & $58 / \mathrm{M}$ & Duodenal ulcer \\
\hline 2 & $2010-07$ & $61 / \mathrm{M}$ & Hypertension, chronic kidney disease \\
\hline 3 & $2010-10$ & $69 / \mathrm{F}$ & Early gastric cancer, laryngeal cancer, hypertension, cerebral infarction \\
\hline 4 & $2012-01$ & $55 / \mathrm{M}$ & Diabetes \\
\hline 5 & $2014-01$ & $65 / \mathrm{M}$ & Hypertension, benign prostate hypertrophy \\
6 & $2014-07$ & $67 / \mathrm{M}$ & None \\
\hline
\end{tabular}
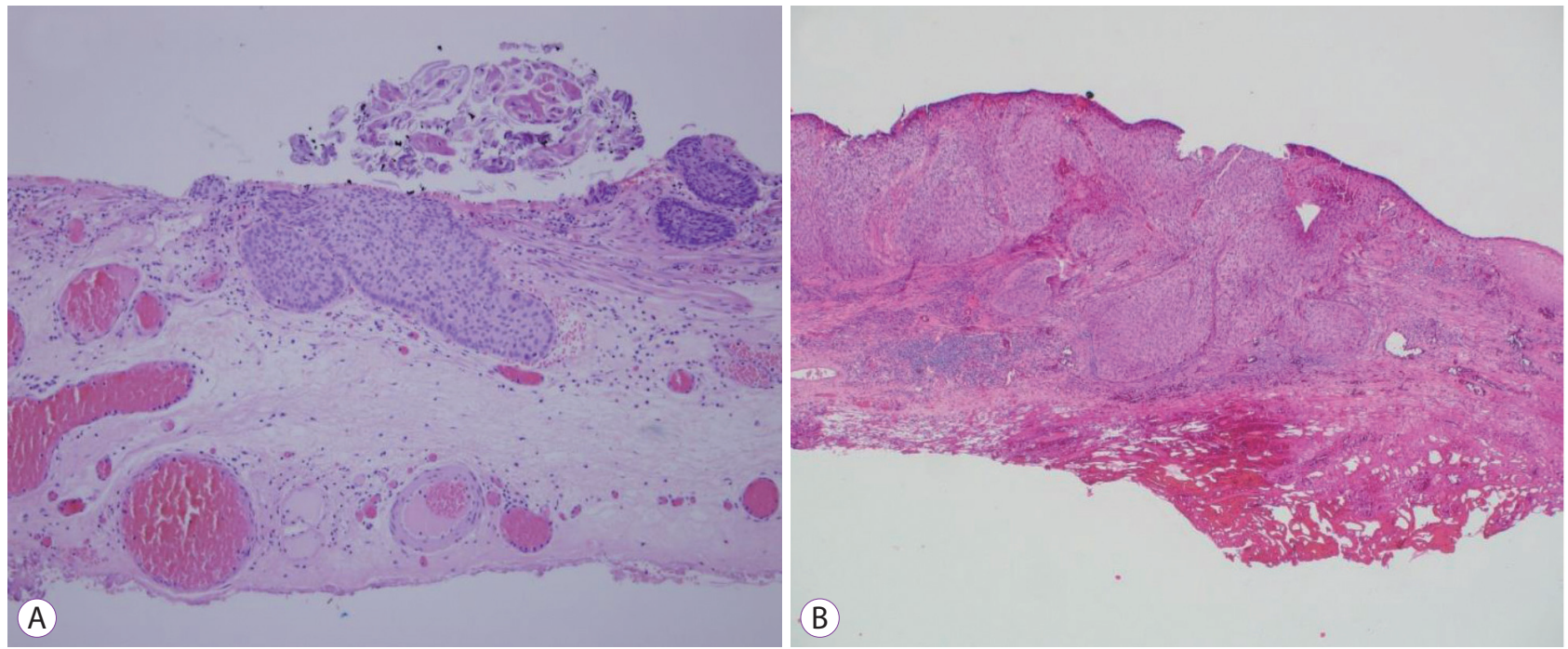

Fig. 2. Cancer-invaded submucosal layer of Patients 2 and 5 are shown in panels (A) and (B), respectively. 
CCRT despite two of the patients having metachronous EEC. However, a limitation of this case series was its small sample size. Although Kawaguchi et al. also reported that ESD followed by CCRT had high efficacy and a strong safety profile for superficial esophageal cancer at M3 or T1, a limitation of their study was that only the CCRT and ESD-CCRT groups were compared. ${ }^{9}$ Despite these limitations, the findings of our study and the study conducted by Kawaguchi et al. suggest that ESD followed by CCRT is a good option for patients with a high risk of lymphatic invasion or resection margin positivity, as determined in the final pathological diagnosis. ${ }^{9}$ Further prospective studies must be conducted to report the effectiveness of CCRT after endoscopic treatment.

\section{Conflicts of Interest}

The authors have no financial conflicts of interest.

\section{REFERENCES}

1. Pennathur A, Gibson MK, Jobe BA, Luketich JD. Oesophageal carcinoma. Lancet 2013;381:400-412.

2. Stilidi I, Davydov M, Bokhyan V, Suleymanov E. Subtotal esophagectomy with extended 2-field lymph node dissection for thoracic esophageal cancer. Eur J Cardiothorac Surg 2003;23:415-420.

3. Saeki $H$, Watanabe M, Mine S, et al. Esophagectomy for superficial esophageal cancer after non-curative endoscopic resection. J Gastroenterol 2015;50:406-413

4. Stahl M, Stuschke M, Lehmann N, et al. Chemoradiation with and without surgery in patients with locally advanced squamous cell carcinoma of the esophagus. J Clin Oncol 2005;23:2310-2317.

5. Bedenne L, Michel P, Bouché O, et al. Chemoradiation followed by surgery compared with chemoradiation alone in squamous cancer of the esophagus: FFCD 9102. J Clin Oncol 2007;25:1160-1168.

6. Oyama T, Tomori A, Hotta K, et al. Endoscopic submucosal dissection of early esophageal cancer. Clin Gastroenterol Hepatol 2005;3(7 Suppl 1):S67-S70

7. Park HC, Kim DH, Gong EJ, et al. Ten-year experience of esophageal endoscopic submucosal dissection of superficial esophageal neoplasms in a single center. Korean J Intern Med 2016;31:1064-1072.

8. Crosby T, Evans M, Gillies RS, Maynard ND. The management of a patient with an operable carcinoma of the oesophagus. Ann R Coll Surg Engl 2009;91:366-370.

9. Kawaguchi G, Sasamoto R, Abe E, et al. The effectiveness of endoscopic submucosal dissection followed by chemoradiotherapy for superficial esophageal cancer. Radiat Oncol 2015;10:31. 